\title{
THE PROFILE OF PERSONAL AUTONOMY IN ATHLETE AND NON-ATHLETE ADOLESCENTS
}

\section{Ştefan TÜDÖS ${ }^{1}$, Georgeta MITRACHE ${ }^{1 *}$, Radu PREDOIU', Ștefan Dănuţ TUDORANCEA ${ }^{2}$}

\author{
${ }^{1}$ National University of Physical Education and Sport, Faculty of Physical Education and Sport, Bucharest, Romania \\ 2 "Grigore Moisil" National College, Bucharest, Romania \\ *Corresponding author: georgetamitrache@gmail.com
}

DOI: 10.35189/iphm.icpesk.2019.49

\begin{abstract}
During adolescence, the individual makes the transition to maturity, their personality and self-concept being intensely developed due to sociocultural environmental factors. Among the essential changes occurring within this stage, rendering its specificity, we mention the development of personal autonomy. This characteristic is defined by self-control and self-determination, being one of the most relevant determinant factors in building efficiency, resilience and psychosocial behaviour in general. On the contrary, low levels of personal autonomy may lead to poor school and professional results, as well as some behavioural disorders. This study aims at identifying the characteristics of personal autonomy in adolescent subjects, by comparing them to age-matched athletes. The participants in this study were 158 students aged 15 years from the "Grigore Moisil" National College in Bucharest. Twenty of them (12.65\%) practice sport on a regular basis. In order to describe the profile of personal autonomy for the subjects through the four related components ("Value component of autonomy", "Behavioural autonomy", "Cognitive autonomy", "Emotional autonomy"), the survey method was used, having as a specific tool the Personal Autonomy (PA) assessment questionnaire, this being part of the Cognitrom Assessment System platform for psychological issues. Using the t-test for independent samples, we have analysed whether there are statistical differences between the surveyed groups: adolescent athletes vs. adolescents who do not engage in systematic sport activities, a comparison regarding the means of the investigated dependent variables - the value component of autonomy, behavioural autonomy, cognitive autonomy and emotional autonomy.
\end{abstract}

Keywords: personal autonomy, value component of autonomy, behavioural autonomy, cognitive autonomy, emotional autonomy.

\section{Introduction}

Adolescence is the stage of life between childhood and adulthood, which, due to the profound mental and psychosomatic transformations that characterise it, can be metaphorically considered as a psychological awakening of the human being. Debesse synthetically expresses the main characteristics of preadolescence and adolescence as: the momentum of the body, the impulse of the heart, the affirmation of the Self, the birth of personal thought and the discovery of the world values (Epuran \& Horghidan, 1994, p. 52). Considered as one of the most important features of personality, the development of personal autonomy and the ability to become independent in thought and action are the central processes of adolescent becoming (Hill \& Holmbeck, 1986). At the same time, adolescence is a period that offers the opportunity to develop personal autonomy. Transformations that occur in adolescence in all subsystems of the human being (physical, cognitive, affective, psychomotor, psychosocial, at personality level), competence development, widening the social field, increasing the social involvement and taking responsibilities, etc. favour the development of personal autonomy. "One of the most important tasks for all adolescents is learning the skills that will help them manage their own lives and make positive, healthy choices. Parents and others can help youth develop this sense of self-governance, responsibility, independence, and decision-making, which are together called autonomy" (Russell \& Bakken, 2002).

The harmonious development of personal autonomy has a particularly important place in the whole process of the adolescent personality transformation: "expressing autonomy and relatedness is related to positive self-esteem, ego development, ego resiliency, friendship competence and educational attainment” (Gitter, 1999, p. 4). "Attributes of autonomy are self-reliance, work orientation, and identity" (Greenberger, 1984).

The importance of autonomy development also results from the fact that it is one of the important determinants of the effectiveness of psychosocial adaptation. As Baltes and Silverberg (1994) demonstrate, personal autonomy can be one of the factors of psychosocial functioning in several areas of social life (such as academic, work and social fields); on the contrary, low personal autonomy can be the cause of low school and professional performance, as well as behavioural disorders (Albu, 2007).

The complexity of the psychosocial phenomenon represented by personal autonomy is reflected in the multitude of theories and the different approaches in the field literature. 
An important aspect taken into consideration in defining autonomy is the ratio of individual (internal environment) - external environment. Thus:

- Several authors consider autonomy as an intrinsic quality, inside the individual. "Inductively, using the empirical process, we have identified three such needs - the needs for competence (Harter, 1978; White, 1963), relatedness (Baumeister \& Leary, 1995; Reis, 1994) and autonomy (deCharms, 1968; Deci, 1975) - that appear to be essential for facilitating optimal functioning of the natural propensities for growth and integration, as well as for constructive social development and personal well-being" (Ryan \& Deci, 2000, p. 68). The above mentioned authors consider autonomy as an intrinsic need of the individual to organize on its own the experiences, behaviours, actions, in accordance with the integrated self.

- Other authors consider that autonomy is totally or partially dependent on the adolescent interpersonal relationships. According to Russell and Bakken (2002), "Adolescents develop autonomy through their relationships in their families and with people outside of their families". Thus, referring to adolescents and their relationships with the family, Hennan, Dornbusch, Herron, \& Herting (1997) define autonomy as a strong feeling of self-identity (which is also maintained under close relationship with parents, but whose elaboration in ontogenesis is favoured by parents who succeed in having supportive, non-coercive and trustworthy relationships with children). Hill and Holmbeck (1986) define autonomy as the freedom to initiate and impose their own actions while maintaining appropriate relationships with important individuals. "Conversely, when adolescents' autonomy is undermined within the parent-child dyad during a disagreement, it has been found that adolescents are more likely to experience internalising behaviours such as depressed affect and anxiety" (Gitter, 1999, p. 4). The systematic practice of a sport branch has a particularly important formative role, giving adolescents the opportunity to exercise their ability of self-govern, their own behaviour and self-control outside the family, both in relation to other young people and to adults and within an activity evaluated by the society.

Concerning the way the freedom of expression is expressed in the formation of personal autonomy, some authors emphasise the phenomenon of mental liberation (for example, Freud, 1958, defines detachment as a progressive liberation from parental control and constraints, and Blos, 1979, defines individualisation as a process of emotional detachment of the adolescent from their parents), and other authors, as the freedom to deliberate, to set goals, to make decisions, the freedom of the person in achieving certain goals, freedom of action, etc. Autonomy expresses a level of freedom and ability to deliberate that cannot be influenced and is easy to take as a psychological feature of self-consciousness and personality (Mamali, cited in Şchiopu, 1997, p. 96).

A defining element of autonomy is that it represents a personality trait. According to the Big-Five Model, Autonomy is one of the five big features of personality (together with extraversion, emotional stability, conscientiousness and agreeableness) (Albu, 2008). It can be an interdisciplinary differentiation criterion. As a personality trait, it develops in ontogenesis under the influence of genetic, educational and environmental factors.

- Personal autonomy is a multidimensional construct: a series of concepts that express the psychological dimensions of personal autonomy can be operationalised: attitudinal, behavioural, emotional, cognitive and value autonomy.

Attitude is a psychological construct (it is complex, sustainable, elaborated throughout life) that involves mental emotional aspects and, mainly, a central evaluation aspect that characterises a person's responses related to an object, class of objects, or phenomenon. Attitudinal autonomy refers to attitudinal independence. The development of attitudinal autonomy at the age of adolescence is conditioned by the cognitive, affective development, but also the development of the capacity for self-appreciation and appreciation, the evaluative capacity, the ability of the individual to think before acting.

Behaviour is the set of adaptive, objectively-observable responses that a system develops to any kind of stimuli (whether external or internal in nature), as well as the whole set of effects of this interaction.

The defining parameters of the behaviour, from an operational point of view, are the sort, the transformation and the finality. The development of behavioural autonomy refers to the development of the capacity of independent functioning, including the control of behaviour and the ability to act according to own decisions.

Emotional processes make up the background and the energy side of mental life and behaviour, having a vital role in triggering, supporting and energetically modifying the adaptive activity (Mitrache \& Predoiu, 2016). At the age of adolescence, the development of emotional autonomy is closely linked to emotional maturity. It is manifested, for example, by the individualisation processes in the relation with parents, colleagues, friends, by gaining emotional independence, as well as the ability to establish harmonious relationships with them. The systematic practice of a sport branch is particularly important for the development of emotional autonomy, the 
emotional processes being closely related to movement: the emotions determine, support and define the movement energetically (emotional reactivity), and any movement is accompanied by affective phenomena.

Cognition represents the group of processes that extract, keep, update and process at different levels the information about the states of the external world and own Self (Mitrache \& Predoiu, 2016). At the age of adolescence, from a functional point of view, the child reaches the highest form of thinking. It acquires the characteristic of double reversibility, which enables to work with abstract notions and develop suppositions, assumptions and theories about reality (in cognitive ontogenesis, this is "the stage of formal operations", according to Piaget).

Developing cognitive autonomy means the development of the adolescent's ability to independently reason, to make decisions in the same time with the development of self-confidence concerning these aspects.

"Value autonomy means having independent attitudes and beliefs regarding spirituality, politics and morals" (Russell \& Bakken, 2002).

- Personal autonomy is defined by self-control and self-determination, being internalised so that the individual has a lasting sense of control over their own life. Aviram and Yonah (2004) define personal autonomy by self-determination, the ability to control own life, as well as the ability to act in a rational manner so as to achieve one's goals.

Recent research on brain transformation at the age of adolescence explains the characteristics of the manifestation of autonomy, as well as the importance of the cultural and educational environment for the future adult personality development. Adolescence provides opportunities for growth, not only in terms of physical dimensions, but also in terms of cognitive and social competence, autonomy, self-esteem and intimacy (Papalia, Olds, \& Feldman, 2010, p. 355).

Research in the field of neuroscience on changes in structure and composition in the frontal cortex (such as the studies by Blakemore \& Choudhury, 2006; Kuhn, 2006) shows that, at the age of adolescence, the volume of white matter in the frontal lobes continues to grow (this phenomenon is typical to brain development in childhood, but also continues during adolescence in the frontal lobes), the most important changes taking place in the prefrontal cortex. This phenomenon causes the processing of information involved in a series of mental functions governed by the prefrontal cortex, such as self-consciousness setting, personal autonomy development in several aspects of adaptation to the social environment (decision-making, self-regulation of behaviour and emotions by anticipating the consequences of actions, understanding the behaviour of others, organization and planning of goal-oriented behaviour, inhibition of undesirable behaviour, etc.), to be different at the age of adolescence compared to adulthood. Thus, in order to solve certain situations or make certain decisions, adolescents and adults use different areas of the brain, meaning that adolescents process information differently from adults. For example, while adults mostly use the prefrontal lobe to respond to different situations, adolescents most often respond using the amygdala. This phenomenon causes adolescents to adopt emotional behaviour, while adults adopt logical behaviour, which explains their tendency to react before processing, understanding and analysing the situation and thee consequences of their actions. Also, the ability to take into consideration someone else's point of view in order to regulate ongoing behaviour is still under development in middle adolescence.

Neuroscience research also demonstrates the importance of education and learning in this stage of life. Thus, at the age of adolescence, a phenomenon takes place through which the brain optimises its activity: a process of eliminating unused dendritic connections (in both the prefrontal cortex and other areas of the brain), thereby increasing brain efficacy. As a result, the synapses that are used by the educational influences of the environment are strengthened and the unused ones are eliminated. Therefore, the educational influences with formative effects on adolescents are of particular importance for their subsequent psychological development (at the psychomotor, cognitive, affective, social, personality levels). In this context, the systematic practice of a sport branch, through its extensive benefits brought to the whole psychosomatic development, can be a very effective way for the harmonious development of the adolescent's personality and personal autonomy. Authors emphasise that autonomy can be fulfilled through sport consumption and is a good predictor of short-term subjective well-being (Kim \& James, 2019).

In the field of sport, autonomy has been mostly studied in connection with coaching activities. Thus, O'Neil and Hodge (2019) talk about the importance of autonomy-supportive coaching style for better involvement of the athletes, while Mahoney, Ntoumanis, Gucciardi, Mallett, \& Stebbings (2016) underline that, in adolescent rowers (but also in adolescent judokas - Delrue, Soenens, Morbée, Vansteenkiste, \& Haerens, 2019), autonomysupportive behaviour must be adapted to contextual pressure, different situations and athletes' personal 
motivation. In their research, Nia and Besharat (2010) argued that individual athletes scored significantly higher for autonomy than team athletes. We mention that there is a lack of studies considering the characteristics of personal autonomy (value, emotional, cognitive and behavioural component of autonomy) in athletes.

Aim

Knowing the characteristics of personal autonomy in adolescents aged 15 years who systematically practice a branch of sport compared to non-athlete students from the "Grigore Moisil" National College.

\section{Assumption}

There are significant differences in personal autonomy between students who systematically practice a sport branch and non-athlete students aged 15 years.

\section{Material and Methods}

\section{Participants}

The participants in this study were 158 students aged 15 years from the "Grigore Moisil" National College in Bucharest. Twenty of them (12.65\%) practice sport on a regular basis and have a competitive experience between 3 and 7 years (Figure 1).

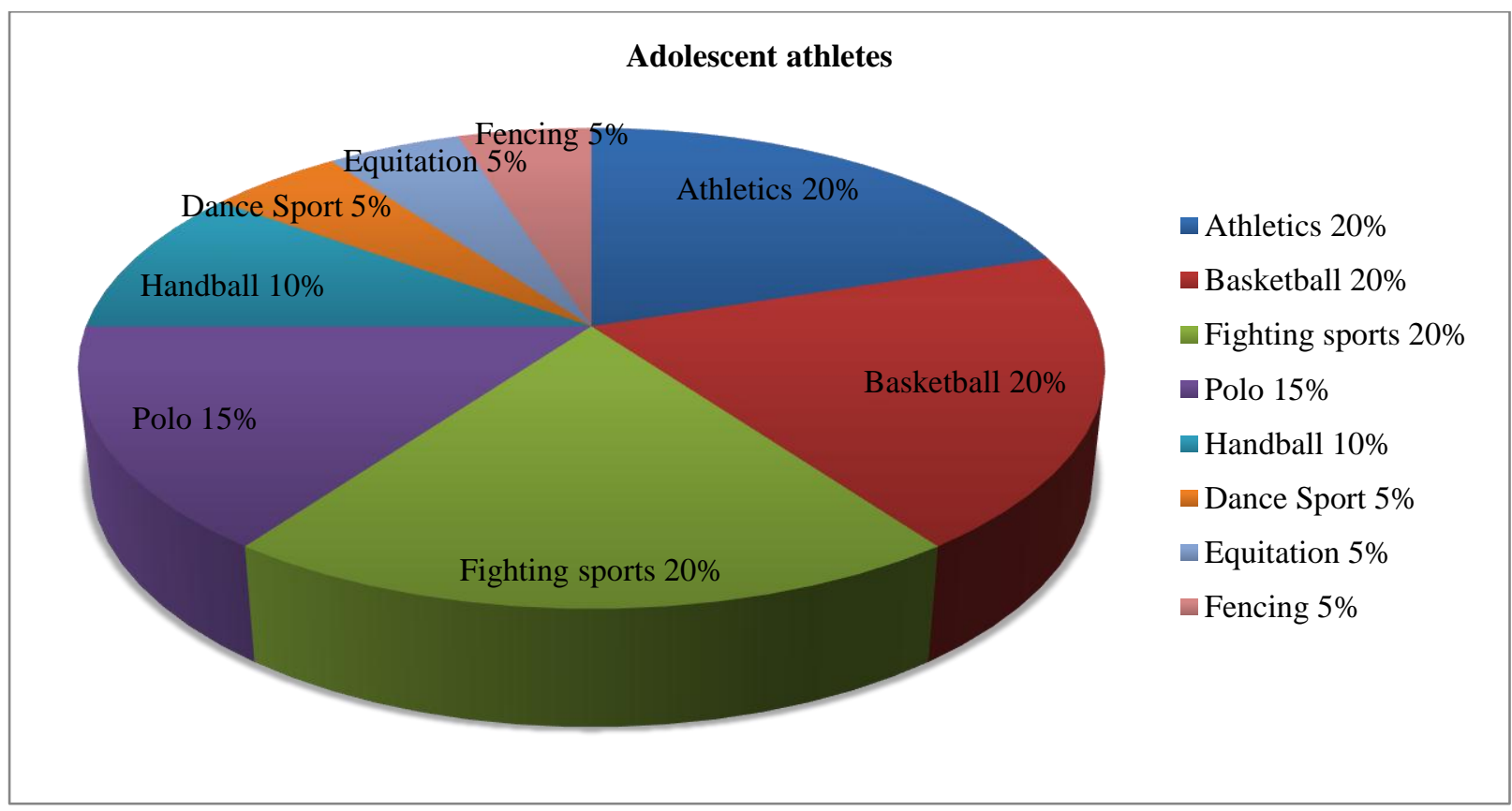

Figure 1. Distribution of adolescents who practice sports

\section{Procedure}

The research was conducted between April and June 2018.

In order to describe the profile of personal autonomy for the subjects through the four related components ("Value component of autonomy", "Behavioural autonomy", "Cognitive autonomy", "Emotional autonomy"), the survey method was used, having as a specific tool the Personal Autonomy (PA) assessment questionnaire, this being part of the Cognitrom Assessment System platform for psychological issues.

\section{Results}

As a result of applying the Personal Autonomy test, the "Personal autonomy - overall score", "Value component of autonomy", "Behavioural autonomy", "Cognitive autonomy", "Emotional autonomy" indicators were calculated. They express the following psychological dimensions: 
- "Personal Autonomy" - according to the test manual, measures the person's ability to control their own life, along with the feeling of being able to put that control into practice (Miclea, Porumb, Cotârlea, \& Albu, 2009, p. 13).

- "Value component of autonomy" - assesses the extent to which the individual has developed their own axiological system, own set of principles and beliefs, resisting the pressure of others (Miclea, Porumb, Cotârlea, \& Albu, 2009, p. 12).

- "Behavioural autonomy" - assesses the individual's level in terms of self-control and self-guidance of behaviour, as well as the individual's ability to act according to their own decisions.

- "Cognitive autonomy" - according to the test manual, assesses the individual's level of independence in thinking and reasoning, ability to express personal opinions and make their own decisions, independence and level of critical thinking, desire to be informed, self-evaluation ability, self-confidence, accompanied by the consciousness that they can choose what to do.

- "Emotional autonomy" - assesses the individual's level of independence in creating and expressing feelings and emotional experiences.

Using the t-test for independent samples, we analysed whether there are statistically differences between the groups surveyed: adolescent athletes vs. adolescents who do not engage in systematic physical activities, a comparison regarding the means of the investigated dependent variables - the value component of autonomy, behavioural autonomy, cognitive autonomy and emotional autonomy. Also, we verified the existence of significant differences between the two groups specified above considering the overall score for Personal Autonomy.

The conditions for applying the t-test are fulfilled: each participant belongs to only one group, and the groups are independent (group independence); the dependent variables are measured on an interval scale; the skewness coefficient in absolute value is less than 1, meaning that the dependent variables are normally distributed (Labăr, 2008 , p. 97). With reference to the homogeneity of variances, the Levene's test results are insignificant ( $>0.05$ ).

Table 1. Adolescent athletes vs. Adolescents who do not engage in systematic physical activities - Descriptive statistics

\begin{tabular}{lcccc}
\hline & Group & $\mathrm{N}$ & $\mathrm{Mean}$ & Std. Deviation \\
\hline \multirow{2}{*}{ Value component of autonomy } & athletes & 20 & 59.55 & 7.00 \\
& non-athletes & 138 & 55.33 & 8.96 \\
Behavioural autonomy & athletes & 20 & 61.05 & 8.62 \\
& non-athletes & 138 & 51.05 & 10.03 \\
Cognitive autonomy & athletes & 20 & 61.10 & 7.42 \\
& non-athletes & 138 & 52.93 & 8.69 \\
Emotional autonomy & athletes & 20 & 57.25 & 11.94 \\
& non-athletes & 138 & 51.81 & 11.18 \\
Personal Autonomy - overall score & athletes & 20 & 63.75 & 9.59 \\
& non-athletes & 138 & 53.64 & 10.41 \\
\hline
\end{tabular}

Regarding the results of the "Non-athlete" group of students in the Personal Autonomy test for all 5 calculated indicators, the mean, in terms of significance value, falls within the "Population Average": Personal Autonomy overall score Meannon-athletes $=53.64$; Value component of autonomy Meannon-athletes $=55.33$; Behavioural autonomy Meannon-athletes = 51.05; Cognitive autonomy Meannon-athletes = 52.93; Emotional autonomy Meannon-athletes $=51.8($ Table 1$)$.

Regarding the results of the "Athlete" group of students (who systematically practice a sport branch) in the Personal Autonomy test, it has been found that the averages are higher compared to the "non-athlete" group for all the calculated indicators: Personal Autonomy - overall score MeanAthletes $=63.75$; Value component of autonomy MeanAthletes $=59.55 ;$ Behavioural autonomy MeanAthletes $=61.05 ;$ Cognitive autonomy MeanAthletes $=61.10$; Emotional autonomy MeanAthletes $=57.25$ (Table 1). 
Table 2. Adolescent athletes vs. Adolescents who do not engage in systematic physical activities

\begin{tabular}{lcccccc}
\hline \multicolumn{1}{c}{ Variables } & \multicolumn{1}{c}{} & \multicolumn{3}{c}{ Confidence interval } \\
\multicolumn{1}{c}{$\mathrm{t}$} & $\mathrm{df}$ & $\mathrm{p}$ & $\mathrm{g}$ & Lower & higher \\
\hline Value component of autonomy & -2.014 & 156 & .046 & 0.48 & -8.35 & -.082 \\
Behavioural autonomy & -4.233 & 156 & .000 & 1.01 & -14.66 & -5.33 \\
Cognitive autonomy & -3.993 & 156 & .000 & 0.95 & -12.20 & -4.12 \\
Emotional autonomy & -2.015 & 156 & .046 & 0.48 & -10.76 & -.108 \\
Personal Autonomy - overall score & -4.094 & 156 & .000 & 0.98 & -14.98 & -5.23 \\
\hline
\end{tabular}

The analysis of the scores recorded for the four components of personal autonomy (value, behavioural, cognitive and emotional) and for personal autonomy as an overall score (Table 2) emphasises:

- the average result for: the value component of autonomy, behavioural autonomy, cognitive autonomy, emotional autonomy and also for Personal Autonomy (regarded as an overall score that includes the four components of autonomy mentioned above), in the case of adolescents practising systematic physical activities, is significantly higher $(\mathrm{p}<.05)$ than the average score obtained by non-athletes.

- Hedges' g (the effect size index) highlights a moderate difference between the results for the value component of autonomy and emotional autonomy obtained by adolescent athletes and the results of adolescents who are not involved in systematic physical activities; also, the effect size index shows a very strong difference between the results for cognitive autonomy, behavioural autonomy and Personal Autonomy (as an overall score) obtained by adolescent athletes and the results of non-athletes.

\section{Discussion and Conclusion}

Regarding the results of the "non-athlete" group of students in the Personal Autonomy test for all 5 calculated indicators, the mean, in terms of significance value, falls within the "Population Average".

The "Athlete" group is characterised, from the personal autonomy perspective, by the following: has the ability to self-assess, to critically analyse the received information, to make decisions independently and to form its own opinions without being influenced by other individuals (Cognitive autonomy - "above population average"); acts according to its own decisions without being influenced by the opinions of others; has the ability to successfully carry out a task and does not give up it if it encounters difficulties; makes efforts to cope alone (Behavioural autonomy - "above population average"); has a high level of personal autonomy (Personal Autonomy - overall score - "above population average").

The analysis of the scores recorded for the four components of personal autonomy (value, behavioural, cognitive and emotional) and for personal autonomy as an overall score emphasises that the average result for the value component of autonomy, behavioural autonomy, cognitive autonomy, emotional autonomy and Personal Autonomy, in the case of adolescents practising systematic physical activities, is significantly higher than the average score obtained by non-athletes.

The effect size index highlights a moderate difference between the results for the value component of autonomy and emotional autonomy obtained by adolescent athletes and the results of adolescents who are not involved in systematic physical activities. Also, Hedges' g shows a strong difference between the results for cognitive autonomy, behavioural autonomy and Personal Autonomy (as an overall score) obtained by adolescent athletes and the results of non-athletes.

We can conclude that the research assumption has been confirmed. The systematic practice of a sport branch influences the harmonious development of personal autonomy. Our results are consistent with those emphasised in the literature (Kim \& James, 2019). Hogg (1995), talking about the humanistic approach, mentions that, after the age of 18, athletes develop their personal autonomy due to: training/competition intensity, self-responsibility, performance routines and strategies. But we need to bring into question Griffin's opinion as well: "Sports is often credited with producing autonomous, independent people. [...] but this idea is much overrated. [...]. Most sports situations are top-down, hierarchical arrangements, with the coach in autocratic control - he sets up the schedule, picks the team, decides who starts and who substitutes. Most athletes only take on responsibility for making tactical decisions - ways of achieving a game strategy decided on by the coach. [...] Effectively carrying out the one's assignment should not be equated with achieving personal independence or self-determination. In fact, it may get in the way of true independence" (Griffin, 1998, p. 63). 


\section{Authors' Contributions}

All authors contributed equally to this study and should be considered as main authors.

\section{References}

Albu, M. (2008). Variaţii ale autonomiei personale în funcţie de vârstă [Variations of personal autonomy according to age]. Analele Institutului de Istorie „, G. Bariţiu” din Cluj-Napoca, VI, 87-104. Retrieved from http://www.history-cluj.ro/SU/anuare/2008/Continut/art05Albu.PDF

Aviram, R., \& Yonah, Y. (2004). 'Flexible control': Towards a conception of personal autonomy for postmodern education. Educational Philosophy and Theory, 36(1), 3-17. https://doi.org/10.1111/j.1469-5812.2004.00045.x

Baltes, M. M., \& Silverberg, S. B. (1994). The dynamics between dependency and autonomy: Illustrations across the life span. In D. L. Featherman, R. M. Lerner, \& M. Perlmutter (Eds.), Life-span development and behaviour (pp. 41-90). Hillsdale: Erlbaum.

Blakemore, S. J., \& Choudhury S. (2006). Development of the adolescent brain: Implications for executive function and social cognition. Journal of Child Psychology and Psychiatry, 47(3-4), 296-312. https://doi.org/10.1111/j.1469-7610.2006.01611.x

Blos, P. (1979). The adolescent passage: Developmental issues. New York: International Universities Press.

Delrue, J., Soenens, B., Morbée, S., Vansteenkiste, M., \& Haerens, L. (2019). Do athletes' responses to coach autonomy support and control depend on the situation and athletes' personal motivation? Psychology of Sport and Exercise, 43, 321-332. https://doi.org/10.1016/j.psychsport.2019.04.003

Epuran, M., \& Horghidan, V. (1994). Psihologia educației fizice [Psychology of physical education]. București: ANEFS.

Freud, A. (1958). Adolescence. Psychoanalytic Study of the Child, 13(1), 255-278. https://doi.org/10.1080/00797308.1958.11823182

Gitter, H. A. (1999). Adolescents' and mothers' models of attachment as predictors of developing autonomy and relatedness in observed family interactions (Distinguished Majors Thesis). University of Virginia. Retrieved from http://www.people.virginia.edu/ psykliff/pubs/publications/alex\%20gitter.pdf

Greenberger, E. (1984). Defining psychosocial maturity in adolescence. Advances in Child Behavioural Analysis \& Therapy, 3, 1-37. Retrieved from https://psycnet.apa.org/record/1984-22820-001

Griffin, R. S. (1998). Sports in the lives of children and adolescents: Success on the field and in life. Westport: Praeger.

Hennan, M. R., Dornbusch, S. M., Herron, M. C., \& Herting, J. R. (1997). The influence of family regulation, connection, and psychological autonomy on six measures of adolescent functioning. Journal of Adolescent Research, 12(1), 34-67. https://doi.org/10.1177\%2F0743554897121004

Hill, J. P., \& Holmbeck, G. N. (1986). Attachment and autonomy during adolescence. In G. J. Whitehurst (Ed.), Annals of child development (pp. 145-189). Greenwich, CN: JAI Press.

Hogg, J. (1995). Mental skills for swim coaches: A swim text on the psychological aspects of competitive swimming. Edmonton, Alberta, Canada: Sport Excel Pub Inc.

Kim, J., \& James, J. D. (2019). Sport and happiness: Understanding the relations among sport consumption activities, long- and short-term subjective well-being, and psychological need fulfillment. Journal of Sport Management, 33(2), 119-132. https://doi.org/10.1123/jsm.2018-0071

Kuhn, D. (2006). Do cognitive changes accompany developments in the adolescent brain? Perspectives on Psychological Science, 1(1), 59-67. https://doi.org/10.1111/j.1745-6924.2006.t01-2-.x

Labăr, A. V. (2008). SPSS pentru ştiinţele educaţiei [SPSS for education sciences]. Iaşi: Polirom.

Mahoney, J. W., Ntoumanis, N., Gucciardi, D. F., Mallett, C. J., \& Stebbings, J. (2016). Implementing an autonomy-supportive intervention to develop mental toughness in adolescent rowers. Journal of Applied Sport Psychology, 28(2), 199-215. https://doi.org/10.1080/10413200.2015.1101030

Miclea, M., Porumb, M., Cotârlea, P., \& Albu, M. (2009). CAS ${ }^{++}$: Personalitate și interese $\left[\right.$CAS ${ }^{++}$: Personality and interest]. Cluj Napoca: ASCR.

Mitrache, G., \& Predoiu, R. (2016). Psihopedagogie. Curs în tehnologia IFR [Psychopedagogy. An IFR technology course]. Bucureşti: Discobolul.

Nia, M. E., \& Besharat, M. A. (2010). Comparison of athletes' personality characteristics in individual and team sports. Procedia - Social and Behavioural Sciences, 5, 808-812. https://doi.org/10.1016/j.sbspro.2010.07.189 
O’Neil, L., \& Hodge, K. (2019). Commitment in sport: The role of coaching style and autonomous versus controlled motivation. Journal of Applied Sport Psychology. https://doi.org/10.1080/10413200.2019.1581302

Papalia, D. E., Olds, S. W., \& Feldman, R. D. (2010). Dezvoltarea umană [Human development]. Bucureşti: Trei.

Russell, S., \& Bakken, R. J. (2002). Development of autonomy in adolescence. Retrieved from https://www.basicknowledge101.com/pdf/Development\%20of\%20Autonomy\%20in\%20Adolescence.pdf

Ryan, R. M., \& Deci, E. L. (2000). Self-determination theory and the facilitation of intrinsic motivation, social development and well-being. American Psychologist, 55(1), 68-78. https://doi.org/10.1037//0003-066x.55.1.68

Şchiopu, U. (Coord.) (1997). Dicţionar de psihologie [Dictionary of psychology]. Bucureşti: Babel. 